\title{
Q. Las multitudes católicas argentinas en la primera mitad del siglo XX. Religión, política y sociedad de masas ${ }^{1}$
}

\author{
Diego Mauro ${ }^{2}$
}

\begin{abstract}
Resumen
El artículo pasa revista a las interpretaciones teóricas e historiográficas sobre los procesos de movilización y conformación de multitudes católicas en la Argentina de la primera mitad del siglo XX. Se analizan los efectos performativos del Ilamado "paradigma clásico" de la secularización y se plantea la necesidad de reubicar los aportes de la perspectiva política, gestada en el contexto de la década de 1980, en un marco explicativo más amplio, capaz de incorporar los aportes recientes de la historia social y cultural. Con dicho propósito se delinea un acercamiento que, basado en el concepto de multitud, pretende poner en diálogo diferentes dimensiones del fenómeno, subrayando su naturaleza poliédrica y su irreductibilidad política e ideológica.
\end{abstract}

Palabras clave: Iglesia católica; secularización; movilización; catolicismo; modernidad.

Catholic crowds in Argentina during the first half of the twentieth century. Religion, politics and mass society

\section{Abstract}

The article analyzes the interpretations of the mobilizations and shaping of Catholic crowds in Argentina during the first half of the twentieth

\footnotetext{
1 Agradezco a los colegas mexicanos con quienes discutí una versión anterior, presentada como conferencia durante el XXIX Congreso Internacional de Historia Regional (Universidad Autónoma de Sinaloa, Culiacán, 7 de diciembre de 2013) y a los participantes del seminario coordinado por Julio de la Cueva Merino y Feliciano Montero (Universidad de Castilla-La Mancha y Universidad de Alcalá de Henares, España, 27 de febrero de 2014), por su generosa acogida y sus valiosas observaciones.

2 Consejo Nacional de Investigaciones Científicas y Técnicas/Universidad Nacional de Rosario. Correo electrónico: diegomauro@conicet.gov.ar
} 
century. First, the text identifies the performative effects of the "classical paradigm" of secularization. Secondly, the article proposes relocating the contributions of the political approach, conceived in the context of the 1980s, in a broader explanatory framework, open to recent contributions of social and cultural history. To this end, the paper proposes a model based on the concept of crowd with the aim of discussing different dimensions of the phenomenon, highlighting its multifaceted nature.

Key words: Catholic Church; secularization; mobilization; Catholicism; modernity.

Fecha de recepción de originales: 18/11/2014.

Fecha de aceptación para su publicación: 11/02/2015.

\section{Las multitudes católicas argentinas en la primera mitad del siglo XX. Religión, política y sociedad de masas}

\section{Introducción}

El aparente declive de la religión en el mundo moderno fue por largo tiempo — uno de los aspectos centrales del Ilamado "paradigma clásico" de la secularización. Reflejo de los presupuestos filosóficos de la sociología decimonónica, según David Martin, este paradigma postulaba la incompatibilidad entre religión y modernidad y, en consecuencia, un proceso más o menos lineal e ineluctable de pérdida de influencia y retracción de la religión; incluso, de virtual extinción en las versiones más ideológicas. En las últimas décadas dichos principios fueron fuertemente rebatidos a través de diversos estudios de caso y nuevas elaboraciones teóricas. Desde la sociología, la antropología y la historia de la religión contemporáneas comenzó a aceptarse poco a poco que la secularización no era ese proceso lineal y necesario de declinación, marginalización y/o privatización de la religión que habían supuesto -y en algunos casos deseado- los filósofos y teóricos "clásicos", sino un proceso mucho menos unidireccional y generalizable, basado en una lógica multidimensional de relocalización y cambio de lo religioso. ${ }^{3}$

En este contexto, la preocupación por la presencia del catolicismo en los espacios públicos y por los procesos de movilización al interior de la Iglesia católica -conceptualizados a veces como "desprivatización"- ganaron una renovada visibilidad científica. En la medida en que la crítica del "viejo

3 Sobre el debate de la secularización la bibliografía es inabarcable: Dobbelaere (1994); Casanova (1994); Diotallevi (2001); McLeod y Ustorf (2003); Hervieu-Léger (2004). 
paradigma" permitía dejar de pensar a las procesiones, peregrinaciones y multitudes católicas como el último estertor de un declive más o menos inevitable, se hacía posible concebirlas teóricamente como emergentes de un proceso de cambio y recomposición global del catolicismo. ${ }^{4}$ Un proceso marcado no solo por el fortalecimiento de los lazos entre Roma y las Iglesias nacionales -la tan mentada romanización- sino también por el surgimiento de un "neocatolicismo" o "catolicismo moderno", dotado de su propio "gran relato" (la "nueva cristiandad" en sus diferentes variantes) y de un laicado militante, organizado en instituciones nacionales e internacionales que se lanzaron a disputar en la esfera pública valiéndose de los mismos recursos de sus adversarios: periódicos, revistas, asociaciones, movilizaciones. ${ }^{5}$

En la Argentina de las décadas finales del siglo XIX y las primeras del XX se vivió un desarrollo similar. Lejos de los postulados del paradigma "clásico", el catolicismo argentino atravesó un proceso de cambio que implicó diversas transformaciones: en un plano, la reconfiguración de las diócesis y la expansión de la estructura parroquial, con la construcción de centenares de templos -sobre todo en la pampa "gringa" - y la emergencia de una Iglesia centralizada que hizo de las diversas corporaciones religiosas provenientes del mundo colonial una institución lo suficientemente cohesionada y diferenciada de la sociedad como para constituir un actor social y político (en 1889 los obispos lograron emitir la primera pastoral colectiva, y a principios del XX se creó el Episcopado) (Di Stefano, 2012); en otro, el surgimiento de numerosas asociaciones de laicos en el seno de las parroquias y a nivel diocesano: los círculos de obreros, grupos orientados a difundir la "Buena Prensa", diversas uniones y ligas electorales, partidos demócratas cristianos en diferentes provincias y, más hacia la entreguerras, las organizaciones de masas impulsadas por Roma, la Unión Popular Católica Argentina (UPCA) y la Acción Católica Argentina (ACA) que, aun con sus diferencias, compartían una visión integralista. ${ }^{6}$

En ese marco, la presencia católica en el espacio público, lejos de languidecer, adquirió una fortaleza que no había tenido a lo largo de todo el siglo

\footnotetext{
4 Uno de los principales obstáculos a vencer en este sentido fue, un tanto paradójicamente, el discurso católico intransigente que irrumpió con fuerza en la segunda mitad del siglo XIX, de la mano del Syllabus y el Concilio Vaticano I, y que consideraba la "secularización" según los cánones del paradigma clásico como una realidad efectivamente existente que había que combatir sin cuartel (Lida, 2007).

5 En esta clave, Clark y Kaiser (2003); Langlois y Sorrel (2009). Para el caso francés: Lagrée (2003), para España: Montero y De la Cueva Merino (2012).

6 Estos temas se encuentran analizados en Blanco (2008); Lida (2009b); Lida y Mauro (2009); Vidal (2010). En términos conceptuales retomamos los planteos clásicos de Poulat $(1977,1984)$. Para el caso argentino, los análisis de Mallimaci (1988) siguen manteniendo su vigencia en ese aspecto. Más recientemente, centrado en los "humanistas cristianos", interesantes reflexiones sobre el integralismo se pueden ver en Zanca (2013).
} 
XIX. La mayor densidad material y asociativa del catolicismo finisecular y la conformación de una Iglesia centralizada favorecieron la movilización católica y ofrecieron condiciones apropiadas para el relanzamiento a nivel nacional de las devociones marianas: una de las más firmes apuestas de Roma en su lucha contra los supuestos males de la modernidad, evidente ya en la sanción del dogma de la Inmaculada Concepción en 1854. ${ }^{7}$ Lourdes primero y Fátima después fueron los grandes modelos a seguir. Con Lourdes, señalan Emma Fattorini $(1997,1999)$ y Sylvie Barnay (2007), el catolicismo enfrentó al laicismo y antepuso el "milagro" al discurso médico científico; con Fátima se embarcó de lleno en la cruzada ideológica anticomunista de entreguerras. Asimismo, hacia fines del siglo XIX se lanzaron desde Roma, alentados especialmente por León XIII, los congresos eucarísticos, cuyo objetivo era colonizar el corazón de las grandes ciudades de Europa y América, y que tendrían amplias repercusiones a nivel mundial.

La Argentina vivió los cambios con intensidad: por un lado, se impulsaron una serie de coronaciones, festividades y aniversarios de las devociones marianas más importantes del país, ubicadas por lo general fuera de las grandes ciudades, en localidades pequeñas o en zonas rurales cercanas a los centros urbanos (Luján, del Valle, Itatí, Guadalupe, de los Milagros, del Rosario, Loreto), lo cual implicó el fortalecimiento de las peregrinaciones y, en muchos casos, su oficialización. Ello suponía -a tono con la conformación de una Iglesia "moderna"- que dejaban de estar en manos de cofradías o instituciones privadas y pasaban a ser organizadas por los propios obispados. Por otro lado, en el centro de las principales ciudades, ganaron renovado vigor celebraciones como Corpus Christi o Cristo Rey -establecida a mediados de la década de 1920 sobre la devoción del Sagrado Corazón- (De la Cueva Merino, 1997, 2000), y comenzaron a celebrarse congresos eucarísticos. En 1916 se realizó el Primer Congreso Eucarístico Nacional, y en la década de 1930 se vivió una verdadera fiebre debido al Congreso Eucarístico Internacional de 1934, que dio pie a una serie de masivos congresos preparatorios en Rosario, Tucumán y Córdoba, así como a semanas eucarísticas en buena parte de las provincias. Si bien no volvieron a repetirse en lo inmediato contingentes de la envergadura de aquéllos (cerca de medio millón de personas en Buenos Aires), el ímpetu movilizador no se aplacó y las multitudes católicas siguieron siendo noticia frecuentemente, en particular durante los congresos eucarísticos nacionales y

7 Al respecto, ver Menozzi y Filoramo (2009). 
en las diversas coronaciones que se sucedieron. ${ }^{8}$ Devinieron, de hecho, en una de las postales más emblemáticas de la Argentina de aquellas décadas, bastante antes por cierto del Ilamado "renacimiento católico" que la historiografía ubicó tradicionalmente en la década de 1930.9

\section{Interpretaciones historiográficas}

Las primeras investigaciones académicas acerca del fenómeno aparecieron con cierta definición en la década de 1980; en ellas se privilegiaba el registro político y se ponían en primer plano los aspectos ideológicos: la retórica integrista de los oradores callejeros -figuras eminentes del clero, obispos y dirigentes del laicado- y la fuerte presencia de la simbología del mito de la nación católica en el desarrollo de las celebraciones y los actos. Las coronaciones, peregrinaciones y congresos se asociaron, de ese modo, a la llamada "reconquista" de la sociedad impulsada por el catolicismo integral y romano, y a la alianza entre la cruz y la espada postulada por los integristas y el nacionalismo católico. En buena medida esta interpretación política implicaba una doble respuesta: tanto a las preocupaciones generales del campo intelectual argentino de los años ochenta -orientadas a desvelar los orígenes de la cultura política autoritaria que había asolado al país-, como a las interpretaciones de una historiografía apologética sobre la Iglesia y el catolicismo que negaba de raíz dicha arista política en beneficio de lecturas estrictamente religiosas y devocionales. ${ }^{10}$

Más recientemente, nuevas investigaciones pusieron de relieve otros aspectos y llamaron la atención, en sintonía con los planteos de Enzo Traverso (2012), sobre la necesidad de diferenciar más claramente el fenómeno de su autorepresentación. ${ }^{11}$ El enfoque político tendía a confundir la historia de las multitudes católicas con la historia de la representación que de ellas proyectaban los sectores integristas y parte de las jerarquías eclesiásticas, particularmente interesadas en alimentar dicha superposición. Para los obispos, nada

8 También diversas organizaciones católicas como los Exploradores de Don Bosco, los Círculos de Obreros y las diferentes ramas de la Acción Católica Argentina mantuvieron una movilización constante en las ciudades, aunque de menor magnitud. Véase Lida (2009a, 2010a); Mauro (2009, 2010); Romero (2010); Tenti (2011, 2014); Rodríguez y Funkner (2013).

9 Sobre el debate acerca del "renacimiento católico", remitirse a Lida (2007, 2010b), Mauro (2008), Lida y Mauro (2009).

10 Algunos trabajos en esta clave en Zanatta (1996), Macor (2005), Ghio (2007).

$11 \mathrm{Al}$ respecto, ver Mauro (2011). Algunas consideraciones teóricas en el marco de los debates sobre el concepto de "religión política" en la historiografía del fascismo en Traverso (2012). 
mejor que asociar las muchedumbres del Congreso Eucarístico de 1934 a la oratoria de Dionisio Napal, que acallaba cualquier duda sobre la supuesta identidad católica de la Argentina. En el marco de una democracia de partidos en crisis, jaqueada por la abstención más o menos forzada del partido mayoritario tras el golpe de Estado del 6 de septiembre de 1930 y signada durante la segunda mitad de la década por la realización sistemática de fraudes masivos, las multitudes católicas cotizaban claramente en alza. ${ }^{12}$ El juego político de las jerarquías eclesiásticas residía precisamente en valerse de ellas como si efectivamente se tratara de movilizaciones de un alto voltaje ideológico.

En términos historiográficos, la confusión de planos se vio alimentada a su vez por el peso que posteriormente adquirió el nacionalismo católico como discurso legitimante durante la última dictadura militar en los años setenta del siglo XX, lo que Ilevó en muchos casos a visualizar las masas católicas de la primera mitad en dicha clave. Por otro lado, el impacto de los conflictos religiosos en países como España y México jugó fortaleciendo interpretativamente el registro político, aun cuando la situación fuera muy diferente en la Argentina. Los oradores católicos apelaban tanto a la guerra cristera como a la guerra civil española y al peligro rojo para arengar a sus públicos, claro está, pero el hecho de que tuvieran que nutrir sus discursos precisamente con crónicas de otras latitudes ponía al mismo tiempo en evidencia la distancia que existía entre Argentina, México, España o la Unión Soviética (Lida, 2010b). Por más que la retórica intentara acercar aquellos escenarios amenazantes, el trecho por recorrer era muy largo. Conflictos como los suscitados en México -al menos hasta el establecimiento del modus vivendi que Roberto Blancarte (1992, p. 58) ubica hacia finales de la década del treinta- o el "anticlericalismo popular" que desata la experiencia republicana y la guerra civil en España no tienen punto de comparación con las manifestaciones del catolicismo de masas y el anticlericalismo argentinos ni encuentran parangón con los conflictos locales en los que se vio envuelta la Iglesia. ${ }^{13} \mathrm{Ni}$ siquiera un nivel de efervescencia como el que rodeó al Congreso Eucarístico Internacional de Madrid en 1911 -tras una década de activa movilización anticlerical popular- se encuentra en la realidad argentina. Con la excepción, tal vez, de los conflictos suscitados por los gobiernos reformistas de la provincia de Santa Fe en los años veinte y treinta. ${ }^{14}$

\footnotetext{
12 Sobre el fraude, ver De Privitellio (2011); Mauro (2013).

13 Por supuesto, cabría diferenciar entre regiones. La intensidad de la guerra no fue igual en el Bajío o en Puebla, por ejemplo. Al respecto, Savarino y Mutolo (2008). En términos generales, Blancarte (1992, 1996). Sobre la recepción del conflicto, Meyer (2010).

14 Al respecto, De la Cueva Merino (1997, 2007); Montero y De la Cueva Merino (2009); Suárez Cortina (2012, 2014); Rodríguez Lago (2013). Para Argentina, Di Stefano (2010); Martínez y Mauro (2012).
} 
Se hace por tanto necesario relocalizar las preguntas del prisma político en un marco explicativo más amplio, en el que se tengan en cuenta las otras facetas del fenómeno, relacionadas con las transformaciones sociales, económicas y culturales que a lo largo de aquellas décadas fueron conformando una sociedad de masas en la Argentina, signada por elevados niveles de urbanización, el impacto de la industrialización por sustitución de importaciones, el crecimiento del consumo y el desarrollo de la prensa comercial, la radio y la cultura de masas (Debord, 1983). Una perspectiva que permita controlar mejor los efectos performativos del concepto de movilización y, de esa manera, contribuya a animar cuadros más poliédricos.

Me parece importante, por consiguiente, diferenciar rigurosamente algunos conceptos centrales como los de movilización, manifestación y multitud, que remiten a fenómenos sustancialmente distintos. Mientras los primeros parten del presupuesto de una cierta homogeneidad, concibiendo a las muchedumbres como el reflejo o la manifestación de una identidad más o menos preexistente (en este caso, una supuesta identidad política católica integralista o integrista); el de multitud, por el contrario, parte del reconocimiento de una heterogeneidad irreductible o, en los términos de Paolo Virno (2003), de una lógica "múltiple". El pasaje teórico del concepto de movilización al de multitud implica, por ende, problematizar el vínculo entre discursos, multitudes, identidades y participación: una relación a todas luces compleja. ¿Qué tan representativas o influyentes eran las homilías y sermones, la estética del mito o los discursos de los diferentes oradores? ¿Qué quedaba de ellos pasado el evento? Y, sobre todo, ¿qué tan definitorios eran a la hora de asegurar una cierta concurrencia? Si ponemos en tensión el espejismo de las movilizaciones de papel retratadas por la prensa, por utilizar una expresión de Pierre Favre (1990) -y con él, la ilusión de un impacto unidireccional entre palabras y audiencias-, la incidencia de aquellas retóricas integristas de combate a nivel de la multitud se vuelve mucho más una incógnita que una certeza, una interesante línea de investigación a transitar antes que un presupuesto válido. Por supuesto, que el impacto no fuera unidireccional no quiere decir que no existiera: en todo caso, será preciso investigar a través de estudios concretos las sinuosas apropiaciones y resignificaciones de esos discursos, es decir, será necesario transitar una historia cultural de la política que parta de reconocer la polisemia constitutiva del discurso y el carácter activo de las audiencias.

Se impone, en consecuencia -y esta es nuestra propuesta al respecto-, recomponer una imagen que trascienda los aspectos políticos y nos ayude a entender finalmente mejor las diferentes lógicas intrínsecas y las potenciales motivaciones de los católicos en las calles. Las investigaciones que realizamos junto 
con otros colegas en los últimos años nos permitieron dar algunos pasos en esa dirección, como intentaremos repasar sucintamente en las próximas páginas.

\section{Las dimensiones de la multitud católica}

A fines del siglo XIX, contingentes como los que se hicieron habituales en los años veinte y treinta hubieran sido materialmente imposibles. El caso del santuario guadalupano, ubicado a unos pocos kilómetros de la ciudad de Santa Fe, constituye un buen ejemplo: los caminos eran casi inexistentes o muy precarios - convertidos en lodazales ante cualquier lluvia- y no existían todavía tranvías o líneas de ómnibus que acercaran el templo a la estación de trenes ubicada en el centro de la ciudad. Solo algunos carros realizaban los traslados, por lo que, como mucho, en esas condiciones, los contingentes se contaban en centenas. El desarrollo de la infraestructura de transportes fue, en este sentido, indispensable para que la curva ascendente de peregrinos pudiera sostenerse hasta alcanzar las decenas de miles de los años treinta. Por entonces, las condiciones habían cambiado totalmente: las frecuencias ferroviarias entre Rosario y Santa Fe se habían duplicado, nuevos y mejores caminos conectaban el santuario con los principales centros urbanos, y la ciudad de Santa Fe contaba ya con varias líneas de tranvías y ómnibus. Existían incluso lanchas que unían la capital santafesina con Paraná. Lo mismo ocurría en otras capitales de provincia y más aún en las principales ciudades como Buenos Aires o Rosario. Durante el Congreso Internacional de 1934, una de las cuestiones más atendidas por las guías que difundían el evento fue precisamente el transporte: las conexiones entre el centro y los barrios, así como entre la ciudad y diferentes puntos de la provincia y del país.

Los escenarios privilegiados para las celebraciones del catolicismo de masas también surgieron al calor de esas primeras décadas del siglo XX, resultado del desarrollo de proyectos urbanísticos nuevos que comenzaban a atender los efectos de la acelerada concentración en las principales ciudades. Las imponentes puestas en escena de la Iglesia de los años treinta deben mucho a esas obras previas capaces de ofrecer a los organizadores católicos ámbitos apropiados y sobre todo perspectivas privilegiadas para las grandes congregaciones: los Bosques de Palermo en Buenos Aires, el Parque Independencia en Rosario -donde confluía el principal boulevard de la ciudad con otras arterias importantes-, la laguna Setúbal y el puente colgante en Santa Fe -nodo de intersección de bulevares y avenidas-, el parque Sarmiento en Córdoba o el 9 de Julio en Tucumán (Gorelik, 2001; Roldán, 2012).

La Iglesia católica, por su parte, intentó acompañar los cambios con 
nuevos y más ambiciosos proyectos edilicios, y dio vida a un buen número de templos que, con sus fachadas neogóticas o neoclásicas, se convirtieron en verdaderos atractivos para los visitantes, al tiempo en que ofrecían condiciones más apropiadas para la reunión de grandes contingentes: naves laterales, explanadas, escalinatas, amplios accesos. De hecho, tras el Congreso Eucarístico Nacional de 1916 comenzó a discutirse cómo modificar la catedral de Buenos Aires para que estuviera más acorde con la pujanza de la ciudad pero además para que pudiera alojar a los crecientes contingentes que la visitaban. En el proyecto de reformas de 1917 se incluyó precisamente, entre otros cambios, el ensanche de la calle aledaña y la construcción de grandes escalinatas (Lida, 2008). En Santa Fe, el crecimiento y la oficialización de la peregrinación al santuario guadalupano se tradujo en la construcción, entre 1904 y 1910, de un nuevo templo neogótico con una torre de sesenta metros que podía divisarse a la distancia. A nivel nacional, el ejemplo probablemente más representativo fue la basílica de Luján: la construcción del templo de estilo neogótico ojival comenzó en 1890 y se concluyó en 1935. Para el Centenario en 1910 se inauguró el interior, y durante la década de 1920 se levantaron las dos torres cuya conclusión coincidió con la celebración del tercer centenario del milagro que había dado origen a la devoción y con el nombramiento oficial del santuario como Basílica. Con sus casi 110 metros de altura, rodeado por amplios espacios abiertos, el templo no tardó en convertirse en el principal centro de peregrinaje del país. Se iniciaron igualmente por aquellos años, en un área rural de la provincia de Corrientes, las obras del Santuario de la Virgen de Itatí, concluidas una década después con la inauguración de un edificio de estilo neoclásico y una cúpula de ochenta metros divisable desde el río Paraná. ${ }^{15}$

Los cambios edilicios no vinieron solos y de la mano de la construcción de los nuevos templos fue haciéndose evidente también la evolución de la capacidad organizativa de las elites católicas. Las más bien precarias y pequeñas comisiones organizadoras de fines del siglo XIX, muy vinculadas a las formas de sociabilidad notabiliares, se fueron sofisticando con el paso de las décadas hasta devenir, hacia los años treinta, en complejas estructuras. Los organigramas que se publicaban en los libros conmemorativos muestran un intrincado y enmarañado mapa de comisiones y subcomisiones basado en una doble lógica transversal y piramidal: por un lado, un conjunto de consejos o comités vinculados horizontalmente y responsables de las grandes decisiones; por otro, una vasta base de delegaciones parroquiales o locales que tenían como propósito Ilevarlas a la práctica. Los comités centrales, a su vez, se dividían según el tipo

15 Ver Mauro (2009); Lida (2010c); Fogelman, Ceva y Touris (2013). 
de actividad que realizaban: propaganda, coordinación, eventos, prensa, planificación, traslados, alojamiento, finanzas, recepción o infraestructura, entre otras. En términos de tecnologías de la organización, los sinuosos laberintos de los organigramas de funciones - habitualmente publicados en los libros conmemorativos- no tenían nada que envidiarle a los que de la misma manera proliferaban por esos años en las grandes empresas capitalistas, en las burocracias estatales o en los consejos de producción de la Unión Soviética.

$\mathrm{Al}$ igual que con las infraestructuras de transporte, sin esos recursos de coordinación y planificación resulta difícil imaginar cómo hubieran podido llevarse a buen puerto eventos de tamaña envergadura, que implicaban tareas, en muchos sentidos, titánicas: empezando por los traslados de miles e incluso decenas de miles de personas, su ordenamiento en las calles, su alojamiento y acceso a los servicios básicos. De hecho, los esfuerzos no siempre alcanzaron. Durante la Coronación de la Virgen de Guadalupe en 1928, las previsiones se vieron ampliamente superadas: los escasos alojamientos disponibles en una capital de provincia como Santa Fe se ocuparon rápidamente y fue preciso apelar de urgencia a vagones dormitorios en las empresas ferroviarias, a clubes y a parroquias. Los inconvenientes volvieron a registrarse en los congresos diocesanos de 1933 en Rosario y Córdoba, donde además se denunciaron alzas de precios y malas condiciones de salubridad e higiene en muchos de los albergues. Aunque Buenos Aires contaba con una infraestructura mucho mayor, la envergadura del Congreso de 1934 también colmó las plazas disponibles y obligó a improvisar. Mejor suerte corrió ya, tras una década de intensa actividad, el Congreso Eucarístico Nacional de 1940, realizado en la ciudad de Santa Fe, cuando se acordó con antelación la creación de varios alojamientos en destacamentos militares y en la Sociedad Rural, y se organizó un registro de benefactores dispuestos a alojar congresistas en sus casas particulares.

En ese plano, uno de los principales desafíos que debieron enfrentar las comisiones fue el costo de las tarifas ferroviarias y, en general, la carestía del transporte. Desde fines del siglo XIX, los comités centrales se empeñaron en conseguir rebajas. Los descuentos podían no ser tan abultados como se deseaba pero siempre lograba ofrecerse alguna facilidad, sobre todo, rebajas en los pasajes de ida y vuelta. Con el transcurso de las décadas y el aumento exponencial de los pasajeros se lograron mejores descuentos y se comenzó a discutir las frecuencias, el número de coches de cada tren o los horarios: uno de los aspectos fundamentales para lograr ampliar el radio de peregrinos y evitar que el tumulto y los agolpamientos en las estaciones desalentaran a los visitantes. Con el aumento de los pasajeros se ensayaron también mecanismos de control más sofisticados. Si a principios de siglo los descuentos simplemente 
se les otorgaban en ventanilla a todos los que viajaban en ciertos días y horarios, en las décadas de 1920 y 1930 se hizo preciso tramitar con antelación el pasaje y demostrar la identidad de "peregrino" o "congresista católico", para lo cual las comisiones preparaban carnets y distribuían sellos entre los párrocos o militantes de la Acción Católica que autorizaban los descuentos. Los trenes, de todos modos, a pesar de los refuerzos, solían resultar insuficientes y debían complementarse con otras formas de locomoción como ómnibus especiales o coches particulares puestos al servicio de los organizadores. Desde la década de 1920, los traslados en automóvil comenzaron a planificarse más centralizadamente al tiempo que, sobre todo en los años treinta, se buscó asegurar en los caminos ayuda mecánica por parte del Automóvil Club Argentino y atención médica de primeros auxilios. Llegado el caso, como ocurrió en el Congreso Nacional de 1940, se apeló también a camiones con acoplado, en la ocasión destinados a trasladar a los alumnos de los colegios católicos más alejados: uno de los insumos básicos de las multitudes y de los grandes coros que solían animar los eventos. Una vez en destino, ya en las inmediaciones de los parques, avenidas y plazas, sobre todo durante las procesiones finales, los contingentes quedaban en manos de los denominados "comisarios" que, dotados de brazaletes como en las manifestaciones fascistas, se encargaban de ordenar las columnas de mujeres, hombres, jóvenes o niños, intentando evitar los desbordes que, no obstante, solían dejar un saldo de desmayos y sofocaciones (Lida, 2009; Mauro, 2010).

Aseguradas las condiciones de posibilidad técnicas y materiales básicas, se planificaban luego las otras dimensiones de la multitud, empezando por la "propiamente" religiosa (Luckmann, 1973).

En las devociones marianas, en sintonía con la senda delineada por Lourdes, dicha arista fue privilegiadamente vehiculizada por el milagro de la sanación. Las propias intervenciones de los obispos no dejaban demasiadas dudas y sugerían que dicho costado funcional y milagroso era explícitamente alentado. Si bien en términos de doctrina se rechazaban las visiones más mecanicistas sobre la intervención mariana, en los hechos, la confusión de planos era abiertamente alentada y constituía una parte esencial del fenómeno religioso: en 1902, por ejemplo, el obispo de Santa Fe, Juan Agustín Boneo, animó a los fieles - pero sobre todo a los enfermos y desvalidos- a pedir milagros porque la virgen "escuchaba a todos por igual". En términos similares, el obispo Antonio Caggiano, en Rosario, sugería invocar a María Auxiliadora para sanar de cuerpo y alma y, por supuesto, igualmente a las vírgenes de Luján y del Rosario.

Las plegarias de los fieles solían combinar estas cuestiones de índole universal, relacionadas con la muerte, la enfermedad, el padecimiento o el 
dolor, con otras más específicas, de naturaleza local o regional. En el caso de Guadalupe o María Auxiliadora, en las ciudades de la pampa agrícola argentina, la protección de las cosechas era uno de los pedidos más recurrentes. Los peregrinos -muchos de ellos, arrendatarios y colonos- iban a Guadalupe, cerca de Santa Fe, para pedir por sus enfermedades y padecimientos, pero muy especialmente por la protección de sus cosechas de las granizadas y las langostas. Los salesianos en Rosario, de igual modo vinculados a arrendatarios del sur santafesino, crearon incluso un seguro agrícola en nombre de la Virgen María Auxiliadora, que ofrecía protección a cambio de una parte de la cosecha, para lo cual se firmaba una suerte de "contrato" con la imagen de la virgen. Los santuarios, además, solían tener libros de peticiones y agradecimientos, parte de los cuales se volcaban luego a las publicaciones oficiales como un modo de fortalecer el costado funcional de la religión, a través del cual se animaba a la concurrencia. ${ }^{16}$

Las crónicas de las jornadas y el registro fotográfico ofrecen, en este sentido, valiosos testimonios de la centralidad de "lo religioso", al tiempo que destacan la gravitación de los aspectos recreativos, donde convergían expresiones de la cultura popular y de la creciente cultura de masas. Las peregrinaciones a los santuarios campestres, habitualmente realizadas en familia, eran para muchos una jornada de recreación en la que se suspendían las rutinas cotidianas y las agotadoras jornadas laborales para dar lugar a una serie de actividades diferentes a las corrientes: paseos, juegos, competencias, carreras, apuestas, picnics al aire libre, almuerzos criollos. Además de los vendedores ambulantes, no pocos restaurantes y rotiserías solían preparar viandas u ofertar menús durante la jornada, a la vez que se ofrecían todo tipo de productos y mercancías. El uso del tiempo libre de las multitudes tuvo ciertamente en el creciente consumo uno de sus rostros más nítidos. Durante los eventos, ser peregrino y congresista comenzó a suponer también, junto con la participación en el ritual litúrgico y en las actividades del programa, la adquisición de determinados productos: desde medallas, estampas, sellos postales o prendedores, hasta platos decorativos, artículos de oficina, vajilla, distintivos, colgantes, escudos, libros y discos. Una verdadera "industria de la fe", como denunciaban los librepensadores, fue in crescendo en torno a estos grandes eventos, tanto en las ciudades como en los santuarios. Por esos años, la venta de objetos de culto se convirtió en una de las fuentes de ingresos más importantes de las comisiones organizadoras, junto con la venta de publicidad; un terreno en el que las multitudes católicas siguieron claramente la curva ascendente del consumo de masas. En el 
Congreso Eucarístico Diocesano de Rosario, en 1933, los ingresos por la venta de objetos recordatorios y de avisos comerciales alcanzaron aproximadamente el cuarenta por ciento de las entradas: más de lo que se había recaudado en todas las parroquias de la diócesis. Ni que hablar de lo ocurrido durante el Congreso Internacional, cuando se dio una verdadera apoteosis de avisos de diferentes empresas nacionales e internacionales: las cervezas Bieckert, Palermo y Quilmes, o las petroleras Yacimientos Petrolíferos Fiscales, Texaco o Shell; el Automóvil Club; los bizcochos Canale o los dulces Noel, entre otras tantas firmas, fueron algunas de las empresas que, junto con innumerables tiendas comerciales (casas de fotografía, de ropa, bazares, bombonerías, librerías), hicieron publicidad aprovechando el evento. Aunque en menor medida, los avisos fluyeron también durante los congresos diocesanos y en las coronaciones y se fueron sofisticando con el paso de los años. En las primeras décadas del siglo se trataba apenas de pequeños avisos impresos sin mayores pretensiones gráficas: un rectángulo con una o dos tipografías diferentes, ubicado en algún recodo de las publicaciones oficiales. Para los años treinta se habían transformado considerablemente $y$, siguiendo los cambios en el discurso publicitario, incorporaban litografías, fotos, colores y diferentes tipografías. Por entonces, además, adoptaban varias modalidades: breves menciones en los boletines impresos o radiales, avisos de página completa en las publicaciones oficiales y en los diarios católicos, anuncios en los altoparlantes o descuentos comerciales y beneficios ofrecidos en forma de talonarios. En este último caso, si bien no se lograban ingresos de caja, se estimulaba a la concurrencia asociando el evento con la posibilidad de consumir en condiciones preferenciales.

Con dichos fines, se resaltaban del mismo modo las bondades e intereses de las sedes. En el caso de las devociones marianas, se insistía en los atractivos de los paisajes campestres, de los cursos de agua -si los había- o de la tranquilidad y la belleza natural de esos ámbitos donde podía escaparse de la vorágine de las grandes ciudades. Tal el caso del santuario guadalupano, donde se ofrecían paseos en lancha por la laguna Setúbal, se resaltaba el ambiente bucólico y los productos regionales: pasteles, dulces, alfajores. Si se trataba de un evento netamente urbano, como en el caso de los congresos, los organizadores destacaban precisamente lo inverso: los atractivos de las grandes ciudades -especialmente sus tiendas y comercios-y, en el caso de Buenos Aires, sus rasgos de gran metrópolis. Con lo cual, los organizadores católicos tenían muy presente que una de las claves del éxito pasaba por reproducir la celebración religiosa en los moldes de la cultura de masas, el consumo y los atractivos de la incipiente industria del turismo. De hecho, durante el Congreso Internacional, los términos congresista y turista se confundieron habitualmente 
en la prensa -incluida la católica-; como en la década anterior los peregrinos guadalupanos habían sido Ilamados habitualmente "excursionistas" desde los diarios. ${ }^{17}$ La Guía Oficial distribuida en 1934 entre los visitantes del Congreso recomendaba paseos turísticos a La Plata o Luján, con sus respectivos museos, parques y calles comerciales, y adjuntaba el croquis de la red de ferrocarriles. Se sugerían incluso excursiones más largas a las sierras de Córdoba, a San Carlos de Bariloche o a Mar del Plata, así como desde las ciudades del interior comenzaban a ofrecerse viajes promocionales para Semana Santa a la ciudad de Buenos Aires o visitas a la Basílica de Luján. ${ }^{18}$

Finalmente, fue muy importante también la capacidad demostrada por las comisiones organizadoras para reproducir lo religioso en el marco de las lógicas de las Ilamadas "sociedades del espectáculo". ${ }^{19}$ El Congreso Eucarístico 1934 alcanzó probablemente los máximos logros, pero la mayoría de los eventos se difundieron y promocionaron en esa tónica. En el caso del Congreso de 1940, se apeló tanto a la "espectacularidad" urbana como a la "espectacularidad" de las propias multitudes, mostrando fotos de las de 1934 e invitando a asistir al "magnífico espectáculo". Los grandes contingentes y las mareas humanas, como analizó Vanessa Schwartz (1998, p. 204) para la París finisecular, constituían en sí mismos factores convocantes que los organizadores católicos supieron aprovechar, ayudados por una amplia cobertura mediática. La propaganda escrita, radial y fílmica que iba aumentado y a la que apuntaban con particular esmero las comisiones, sugiere precisamente la importancia adquirida por este tipo de interpelación. Los programas, los avisos y los afiches, los suplementos periodísticos o los micros radiales insistían en la excepcionalidad de los eventos, en que se trataba de "grandes acontecimientos", de "magníficos espectáculos", de "hechos imperdibles" e "inolvidables". Y efectivamente lo eran, puesto que se ponían en acto una amplia gama de recursos para atraer y entretener que se planificaban minuciosamente: desde la actuación de bandas de música y multitudinarios coros hasta la construcción de sofisticados escenarios, el lanzamiento de fuegos artificiales, la detonación de bombas de estruendo o el uso de reflectores, generosamente provistos por la Armada. Cuando les fue posible, los organizadores apelaron también al vuelo de aeroplanos que, como durante la coronación de la Virgen de Guadalupe en 1928, causaron verdadera fascinación. En las celebraciones de la Virgen de Loreto, consagrada

17 Sobre el rol de la prensa, remitirse a Galíndez (2010).

18 Véase Lida (2009a, 2009b); Mauro (2015).

19 Al respecto pueden consultarse Debord (1989); Schwartz (1998). 
patrona de la aviación por Benedicto XV, la presencia de aviones provistos por el Aeroclub de Santiago del Estero se hizo habitual e incluso, como ocurrió en 1929 con motivo de la bendición de la nueva campana del templo, algunos de ellos aterrizaron en una improvisada pista en las inmediaciones, desatando el delirio de los presentes. ${ }^{20}$ Se montaban además, como seguía con atención la prensa, complejas conexiones radiotelefónicas y extensas redes de altoparlantes en las calles para que los asistentes pudieran entonar los cantos, seguir las celebraciones y, cuando los avances técnicos lo permitieron, escuchar la transmisión en directo de la palabra del Papa desde el Vaticano. Tal como se intentó regularmente con diferentes grados de éxito en los congresos eucarísticos que se sucedieron entre 1933 y 1944 (Mauro, 2015). Años en los cuales, tras décadas de intensas transformaciones, la Iglesia católica devino finalmente uno de los actores más convocantes, capaz de recrear imponentes "mares de cabezas" a lo largo y a lo ancho del país.

\section{Conclusiones}

El recorrido historiográfico realizado confirma, en mi opinión, la necesidad de reubicar la dimensión política de las calles católicas en un marco explicativo más amplio que conjugue diferentes aspectos, así como el aporte teórico del concepto de multitud, entendido como el resultado de la convergencia de dinámicas heterogéneas. Como un fenómeno de naturaleza poliédrica irreductible a único registro (el político-ideológico) o a las intenciones de un único actor, aun cuando los oradores de turno -sobre los que se ha centrado mayormente la historiografía- apelaran a los contenidos y a los símbolos del mito de la nación católica para borrar precisamente esa multidimensionalidad. Una operación política particularmente redituable en el contexto de los años treinta.

Las marcas de la heterogeneidad de las muchedumbres estaban, sin embargo, allí, a la vista de todos: en los afiches y los panfletos que circularon, en las promociones de las grandes tiendas, en las ofertas turísticas, en los cientos de vendedores, en las plegarias de los peregrinos y, muy especialmente, en el propio discurso de las comisiones organizadoras. Uno de los mejores testimonios de la lógica múltiple de las multitudes fue precisamente el accionar de las comisiones que, más allá de compartir los principios ideológicos del catolicismo integral e incluso integrista, solo circunstancialmente optaron por apelar a ellos a la hora de convocar a gran escala. Por el contrario, sus estrategias de

20 Acerca de la Virgen de Loreto, Tenti (2011). Sobre la aviación en Alemania, Fritzsche (1992). 
difusión y propaganda se basaron en la cultura popular y de masas, poniendo en diálogo la funcionalidad religiosa -sobre la que insistían los obispos- con las lógicas del espectáculo, la propaganda, la recreación, la industria cultural y el creciente consumo. En este sentido, las claves del éxito del catolicismo de masas parecen haber residido más que en los contenidos ideológicos-de todos modos presentes y sin dudas significativos en los círculos militantes-, en su plasticidad a la hora de articularse con las gramáticas de la masificación social, reproduciendo la religión y lo religioso en los moldes de la industria cultural.

El rostro político de la multitud católica se construyó por tanto a partir de una suerte de doble estándar: por un lado, las "multitudes de escenario", claras y contundentes, dominadas por los oradores e imbuidas de un clima de cruzada, presentadas como la expresión de una identidad política homogénea y disciplinada y como la prueba irrefutable de la validez del mito de la nación católica y, consecuentemente, del lugar central que le cabía ocupar a la Iglesia en la vida política argentina. Por otro, tal como hemos repasado en este artículo, las multitudes de carne y hueso que se congregaban en las calles, debajo de las tarimas y los púlpitos, y a las que se convocaba en buena medida "olvidándose" del mito, a través de una rigurosa y cuidada organización, desplegando un abanico de argumentos y estímulos a tono con la emergente Argentina de masas.

\section{Referencias bibliográficas}

1. Barnay, S. (2007). II rinnovamento della teologia e del culto mariano. En A. Corbin (a cura di) Storia del cristianesimo (pp. 368-371). Milano-Torino: Mondadori.

2. Blancarte, R. (1992). Historia de la Iglesia católica en México. México: Fondo de Cultura Económica.

3. Blancarte, R. (Comp.) (1996). El pensamiento social de los católicos mexicanos. México: Fondo de Cultura Económica.

4. Blanco, J. (2008). Modernidad conservadora y cultura política. La Acción Católica Argentina (1931-1941). Córdoba: Editorial de la Facultad de Filosofía y Humanidades de la Universidad Nacional de Córdoba.

5. Casanova, J. (1994). Public Religions in the Modern World. Chicago: University of Chicago Press.

6. Clark, C. y Kaiser, W. (2003). Culture Wars. Secular-Catholic Conflict in Nineteenth Century Europe. Cambridge: Cambridge University Press. DOI: 10.1017/CBO9780511496714 
7. De La Cueva Merino, J. (1997). Movilización, política e identidad anticlerical, 1898-1910. Ayer, 27, 101-112.

8. De La Cueva Merino, J. (2000). Católicos en la calle: la movilización de los católicos españoles, 1899-1923. Historia y Política, 3, 55-80.

9. De La Cueva Merino, J. (2007). La secularización conflictiva, 1898-1931. Madrid: Editorial Biblioteca Nueva.

10. Debord, G. (1983). Society of the Spectacle. Detroit: Black and Red.

11. De Privitellio, L. (2011). Las elecciones entre dos reformas: 1900-1955. En H. Sábato, M. Ternavasio, L. De Privitellio y A. Persello, Historia de las elecciones en la Argentina (pp. 135-234). Buenos Aires: El Ateneo.

12. Di Stefano, R. (2010). Ovejas Negras. Historia de los anticlericales argentinos. Buenos Aires: Sudamericana.

13. Di Stefano, R. (2012). ¿De qué hablamos cuando decimos 'Iglesia'? Reflexiones sobre el uso historiográfico de un término polisémico. Ariadna Histórica. Lenguajes, Conceptos, Metáforas, 1, 195-220.

14. Diotallevi, L. (2001). Il rompicapo della secolarizzazione italiana. Caso italiano, teorie americane e revisione del paradigma della secolarizzazione. Soveria Mannelli: Rubbettino Editore.

15. Dobbelaere, K. (1994). La secularización: un concepto multidimensional. México: Universidad Iberoamericana.

16. Fattorini, E. (1997). Santi, culti, simboli nell'età della secolarizzazione (1815-1915). Torino: Rosenberg \& Sellier.

17. Fattorini, E. (1999). Il culto mariano tra ottocento e novecento. Simboli e devozione. Ipotesi e prospettive di ricerca. Milán: Franco Angeli.

18. Favre, P. (1990). La Manifestation. París: Presses de la Fondation Nationale des Sciences Politiques.

19. Fogelman, P., Ceva, P. y Touris, C. (2013). El culto mariano en Luján y San Nicolás. Religiosidad e historia regional. Buenos Aires: Biblos.

20. Fritzsche, P. (1992). A Nation of Fliers: German Aviation and the Popular Imagination. Cambridge: Harvard University Press.

21. Galíndez, M. (2010). Prensa y cultura de movilización de masas en el Congreso Eucarístico Internacional de 1934. Ecos de la Historia, 6, 2-9.

22. Ghio, J. (2007). La iglesia católica en la política argentina. Buenos Aires: Prometeo.

23. Gorelik, A. (2001). La Grilla y el Parque. Buenos Aires: Universidad Nacional de Quilmes.

24. Hervieu-Léger, D. (2004). El peregrino y el convertido: la religión en movimiento. México: Ediciones del Helénico.

25. Lagrée, M. (2003). The impact of technology on Catholicism in France 
(1850-1950). En H. McLeod y W. Ustorf (Eds.) The Decline of Christendom in Western Europe, 1750-2000 (pp. 201-217). Cambridge: Cambridge University Press. DOI: 10.1017/CBO9780511496783.011

26. Langlois, C. y Sorrel, C. (Dirs.) (2009). Le catholicisme en congrès (XIXeXXe siècles). Lyon: LARHRA-RESEA, Chrétiens et Sociétés, Documents et Mémoires $\mathrm{n}^{\circ} 8$.

27. Lida, M. (2007). La Iglesia católica en las más recientes historiografías de México y la Argentina. Modernidad y secularización. Historia Mexicana, LVI (4), 1393-1436.

28. Lida, M. (2008). La Catedral en la Penitenciaría: Historia de un fastuoso proyecto urbanístico para Buenos Aires (1934). Temas de Historia Argentina y Americana, 13, 75-100.

29. Lida, M. y Mauro, D. (2009). Catolicismo y sociedad de masas en Argentina: 1900-1950. Rosario: Prohistoria.

30. Lida, M. (2009a). Los Congresos Eucarísticos en la Argentina del siglo XX. Investigaciones y Ensayos, 58, 285-324.

31. Lida, M. (2009b). Los orígenes del catolicismo de masas en la Argentina, 1900-1930. Jahrbuch für Geschichte Lateinamerikas, 46, 345-370. DOI: 10.7767/jbla.2009.46.1.345

32. Lida, M. (2010a). El catolicismo de masas en la década de 1930. Un debate historiográfico. En S. Amenta y C. Folquer (Eds.) Sociedad, cristianismo y política. Tejiendo historias locales (pp. 395-424). Tucumán: Centro Promocional de Investigaciones en Historia y Antropología.

33. Lida, M. (2010b). La cuestión mexicana en el catolicismo argentino de la década de 1920. En J. Meyer (Dir.) Las naciones frente al conflicto religioso en México (pp. 117-138). México: Tusquets.

34. Lida, M. (2010c). ¡A Luján! Las comunidades de inmigrantes y el naciente catolicismo de masas en la Argentina, 1910-1934. Revista de Indias, 250, 809-836.

35. Luckmann, T. (1973). La religión invisible. El problema de la religión en la sociedad moderna. Salamanca: Sígueme.

36. Macor, D. (2005). Católicos e identidad política. En Nación y provincia en la crisis de los años treinta (pp. 179-198). Santa Fe: Universidad Nacional del Litoral.

37. Mallimaci, F. (1988). El catolicismo integral en la Argentina. Buenos Aires: Biblos.

38. Martínez I. y Mauro, D. (Eds.) (2012). Ovejas, lobos y pastores. Debatir la historia del anticlericalismo en la Argentina. Prismas, 16, 205-219.

39. Mauro, D. (2008). Imágenes especulares. La educación entre la laicidad y 
el catolicismo. Santa Fe, 1900-1935. Prohistoria, 12, 103-116.

40. Mauro, D. (2009). La Virgen de Guadalupe en Argentina. Movilización y política en el catolicismo. Santa Fe, 1921-1928. Secuencia, 75, 43-65.

41. Mauro, D. (2010). De los templos a las calles. Catolicismo, sociedad y política. Santa Fe, 1900-1937. Santa Fe: Universidad Nacional del Litoral.

42. Mauro, D. (2011). Multitudes y movilizaciones católicas en la Argentina de entreguerras. Cuestiones teóricas y metodológicas. PolHis, 8 (2). Disponible en: http://historiapolitica.com/datos/boletin/polhis8_MAURO.pdf

43. Mauro, D. (2013). Reformismo liberal y política de masas. Radicales y demócratas progresistas en Santa Fe, 1921-1937. Rosario: Prohistoria.

44. Mauro, D. (2015). Multitudes católicas, sociedad de masas y política en la Argentina. Reflexiones a partir del Congreso Eucarístico Nacional de 1940. Secuencia, 96, en prensa.

45. Mcleod, H. y Ustorf, W. (Eds.) (2003). The Decline of Christendom in Western Europe, 1750-2000. Cambridge: Cambridge University Press. DOI: 10.1017/CBO9780511496783

46. Menozzi, D. y Filoramo, G. (2009). Storia del cristianesimo. L'età contemporánea. Roma: Laterza.

47. Meyer, J. (Comp.) (2010). Las naciones frente al conflicto religioso en México. México: Tusquets.

48. Montero, F. y De La Cueva Merino, J. (2009). Laicismo y catolicismo. El conflicto político-religioso en la Segunda República. Alcalá de Henares: Universidad de Alcalá de Henares.

49. Montero, F. y De La Cueva Merino, J. (Eds.) (2012). Izquierda obrera y religión en España (1900-1939). Alcalá de Henares: Universidad de Alcalá de Henares.

50. Poulat, E. (1977). Integrisme et catholicisme integral. París: Casterman.

51. Poulat, E. (1984). Chiesa contro Borghesia. Italia: Marietti.

52. Rodriguez, A. y Funkner, M. (2013). ¡Viva María Auxiliadora! ¡Viva Don Bosco! ¡Vivan los peregrinos! Las peregrinaciones al Santuario de María Auxiliadora en La Pampa. En A. Rodríguez (Ed.) Estudios de Historia Religiosa Argentina (pp. 107-118). Rosario: Prohistoria.

53. Rodríguez Lago, J. (2013). La Iglesia católica y la II República: resistencias, progresos y retos pendientes. Hispania Nova, 11. Disponible en: http:// hispanianova.rediris.es.

54. Roldán, D. (2012). La invención de las masas. Ciudad, corporalidades y cultura. Rosario, 1910-1945. La Plata: Editorial de la Universidad Nacional de La Plata.

55. Romero, L. A. (2010). El ejército de Cristo Rey. Movilización católica en 
Buenos Aires, 1934-1945. Cuadernos de Historia, 32, 77-98.

56. Savarino, F. y Mutolo, A. (Coords.) (2008). El anticlericalismo en México. México: Porrúa.

57. Schwartz, V. (1998). Spectacular Realities. Early Mass Culture in Fin-desiécle París. Berkeley: University of California Press.

58. Suárez Cortina, M. (Ed.) (2012). Cuestión religiosa. España y México en la época liberal. Cantabria: Ediciones Universidad de Cantabria.

59. Suárez Cortina, M. (2014). Entre cirios y garrotes. Política y religión en la España contemporánea, 1808-1936. Cantabria: Ediciones de la Universidad de Cantabria.

60. Tenti, M. (2011). Loreto: festividad, inundación y después. Las festividades de Nuestra Señora de Loreto en Santiago del Estero, antes y después de la inundación de 1908. Boletín Americanista, 62, 117-134.

61. Tenti, M. (2014). Catolicismo de masas en Santiago del Estero: la festividad del Señor de los Milagros a principios del siglo XX. En A. Aguirre y E. Abalo (Coords.) Representaciones sobre historia y sociedad. Deshaciendo fronteras (pp. 191-210). Rosario: Prohistoria.

62. Traverso, E. (2012). Fascismos. Sobre George Mosse, Zeev Sternhell y Emilio Gentile. En La historia como campo de batalla (pp. 105-144). Buenos Aires: Fondo de Cultura Económica.

63. Vidal, G. (2010). Intentos de centralización desde el Papado: la Unión Popular Católica Argentina en Córdoba. En G. Vidal y J. Blanco (Comps.) Catolicismo y política en Córdoba, Siglos XIX y XX (pp. 83-110). Córdoba: Ferreyra Editor.

64. Virno, P. (2003). Gramáticas de la multitud. Madrid: Traficantes de Sueños.

65. Zanatta, L. (1996). Del Estado liberal a la nación católica. Iglesia y Ejército en los orígenes del peronismo, 1930-1943. Buenos Aires: Universidad Nacional de Quilmes.

66. Zanca, J. (2013). Católicos antifascistas. Buenos Aires: Siglo XXI. 